\title{
Đánh giá liêm chính học thuật của sinh viên qua nhận thức của sinh viên về môi trường học thuật và hành vi không trung thực học thuật
}

\section{An evaluation of student's academic intergrity by their perception on academic environment and dishonesty behaviours}

\author{
Đặng Hùng Vũ ${ }^{1 *}$, Nguyễn Thành Long ${ }^{2}$ \\ ${ }^{1}$ Trường Đại học An Giang - Đại học quốc gia Thành phố Hồ Chí Minh, Việt Nam \\ ${ }^{2}$ Trường Đại học Trà Vinh, Việt Nam \\ *Tác giả liên hệ, Email: dhvu@agu.edu.vn
}

THÔNG TIN

TÓM TĂ T

DOI: $10.46223 /$ HCMCOUJS. econ.vi.16.1.1389.2021

Ngày nhận: 16/04/2020

Ngày nhận lại: 14/07/2020

Duyệt đăng: 16/09/2020

\section{Tù khóa:}

liêm chính học thuật, môi trường học thuật, sinh viên đại học, không trung thực học thuật

Keywords:

academic intergrity, academic environment, undergraduate students, academic dishonesty
Nghiên cứu này khảo sát nhận thức và hành vi không trung thực học thuật, qua đó đánh giá liêm chính học thuật của sinh viên đại học trong bối cảnh của Việt Nam. Nghiên cứu được thực hiện qua cuộc khảo sát 208 sinh viên từ năm thứ nhất đến năm tư của một khoa trong một trường đại học phía Nam tại Việt Nam. Thống kê mô tả được sử dụng để trình bày kết quả khảo sát nhận thức về môi trường học thuật, liêm chính học thuật hành vi không trung thực học thuật của sinh viên. Sự ảnh hưởng của các yếu tố môi trường học thuật và nhân khẩu học đến nhận thức và hành vi không trung thực học thuật được kiểm định qua phân tích sự khác biệt. Mặc dù sinh viên đánh giá rằng quy định của nhà trường về liêm chính học thuật là nghiêm khắc, họ cho rằng hành vi không trung thực học thuật vẫn diễn ra thường xuyên. Kết quả nghiên cứu cho thấy mức độ thường xuyên thực hiện hành vi không trung thực học thuật tương quan trái chiều với mức độ nhận thức thấp của sinh viên về hành vi này. Nhà trường cần phải kiến tạo môi trường học thuật để phát triển liêm chính học thuật.

\section{ABSTRACT}

This study investigated undergraduate students' perception and dishonesty behaviors, by which academic integrity was evaluated in the context of Vietnam. The study was conducted with a survey of 208 undergraduate students from year 1 to year 4 in a faculty of a university in Southern Vietnam. Descriptive statistic data was used to present students' perception of the academic environment, academic integrity and dishonesty behaviors. Kendall's Tau, Sommer's and Goodmann \& Kruskal's gamma were used to test the relationship of the academic environment, demographic factors, student's perception and behaviors in terms of academic integrity. The students reported that dishonesty behaviors were serious, although regulations on academic integrity were said to be strict. Results showed that academic dishonesty behaviors of undergraduate students were associated with their low perception of these behaviors. The university should pay more attention to improve the academic environment in terms of integrity. 


\section{Giới thiệu}

Liêm chính học thuật là cách hành xử ngay thẳng, trung thực và trong sạch trong hoạt động học thuật như học tập, giảng dạy, nghiên cứu và các hoạt động sáng tác, sáng tạo khác. Vi phạm liêm chính học thuật trong các cơ sở giáo dục đào tạo và nghiên cứu là vấn nạn toàn cầu. Trong lĩnh vực khoa học xã hội và nhân văn, Tạp chí Science đã phân tích 767.000 bài báo khoa học gửi qua arXiv.org từ 1991 đến 2011. Kết quả cho thấy đạo văn diễn ra khắp nơi trên thế giới với các mức độ khác nhau thể hiện qua một bản đồ đạo văn. Trong đó, Việt Nam có tần suất đạo văn là $15 \%$ so với mức cao nhất là $20 \%$. Có một phần mười sáu tác giả tự đạo văn và một phần nghìn phạm lỗi không dẫn nguồn (Amirta, 2014; Bohannon, 2017).

Đã có nhiều nghiên cứu lý thuyết và thực nghiệm, ứng dụng về liêm chính học thuật. Một số trong đó cho kết quả đáng chú ý như sau. Hơn một phần ba trong 6.000 sinh viên thuộc 31 trường đại học cao đẳng Hoa Kỳ thừa nhận gian dối học thuật (McCabe \& Trevino, 1997); khoảng $30 \%$ đến $96 \%$ trong mẫu: 1.056 sinh viên ngành kinh doanh bậc đại học và sau đại học tham gia gian dối học thuật thuộc 06 trường đại học ở Hoa Kỳ (Nonis \& Swift, 2001); các hành vi gian lận có xu hướng gia tăng qua tổng kết 10 năm (1991-2000) nghiên cứu tại các trường đại học cao đẳng (McCabe, Trevino, \& Butterfield, 2001a); sinh viên Trung Hoa đại lục $(\mathrm{N}=368)$ và Đài Loan $(\mathrm{N}=237)$ đều vi phạm liêm chính học thuật, nhưng tỉ lệ ở sinh viên Đài Loan thấp hơn (Yang, Chiang, \& Huang, 2017); có 40\% đến $60 \%$ sinh viên ở Botswana và Zimabue đã từng thực hiện một hành vi gian lận (Akakandelwa, Jain, \& Wamundila, 2013).

Đến nay, chưa tìm thấy nghiên cứu tổng thể nào về liêm chính học thuật ở Việt Nam nói chung và trong khoa học xã hội và nhân văn nói riêng. Tuy nhiên, có thể thấy qua phương tiện đại chúng, các sự kiện vi phạm liêm chính học thuật diễn ra gần đây không ít và có thể nói, vài sự việc là nghiêm trọng (Phuong Anh, 2010; Thu Quynh, 2019). Hiện tượng đạo văn trong giới học thuật, trong đó có tác giả ma có lẽ được nói đến nhiều nhất ở gần đây đều trong lĩnh vực khoa học xã hội và nhân văn. Những người được cho là vi phạm đạo văn với những bằng chứng cụ thể đã đều có học vị tiến sĩ, thậm chí có học hàm phó giáo sư, có khi đang nắm một chức vụ quản lý quan trọng ở một viện, trung tâm nghiên cứu, tạp chí. Các biện pháp xử lý vi phạm học thuật trong các trường hợp này được cho là chưa thỏa đáng, kém nghiêm minh (Kien Van, 2019; Nghiem Hue, 2018; Nguyen, 2019a, 2019b; Tầm nhìn, 2019). Cá biệt, một phó giáo sư, tiến sĩ khác đã giành lại học vị, học hàm theo phán quyết của tòa án sau khi Bộ Giáo dục Đào tạo ra quyết định thu bằng vì đạo văn (Ngoc Quang, 2019; Quang Minh, 2019).

Về phía người học ( $\sinh$ viên, học sinh), sự xuất hiện công khai của các trang web làm luận văn, luận án thuê cũng như các chợ luận văn, luận án như minh chứng cho tình hình liêm chính học thuật đang xấu đi (Thu Quynh, 2019), vì đây thực sự là nguồn tài nguyên rẻ tiền cho đạo văn. Hiện tượng gian lận bằng học thuê, thi thuê ở các trường đại học, cao đẳng cũng nở rộ mà chưa có phương cách đối phó hữu hiệu (Hien Le, 2018; Ngoc Mai, 2018). Gần đây, vụ gian lận thi cử để vào đại học tạo ra một thách thức lớn cho nỗ lực gầy dựng liêm chính học thuật, và gây ra các mối quan ngại cho thế hệ thương lai (V. D. Tran, 2019a, 2019b).

Hiện tượng không trung thực học thuật của sinh viên như: đạo văn, gian dối, bịa đặt, hỗ trợ không chính đáng ở các trường đại học Việt Nam là một thực tế, bằng chứng là nhiều trường đã công bố các quy định đặc thù về liêm chính học thuật (Học viện Ngân hàng, 2019; Trường Đại học Bách Khoa-ĐH Đà Nẵng, 2017; Trường Đại học Hoa Sen, 2013); một số trường trang bị cả phần mềm chống đạo văn (Nguyen Thao, 2018). Tuy nhiên, trái với sự phong phú tin bài của phương tiện truyền thông, các nghiên cứu về chủ đề này còn rất ít, đặc biệt là nghiên cứu thực nghiệm. Do vậy, cần nhiều hơn nữa các nghiên cứu về chủ đề này. 
Nghiên cứu này tập trung khảo sát (1) hành vi không trung thực học thuật trong sinh viên (2) nhận thức của họ về các hành vi đó cùng (3) các yếu tố môi trường học thuật (chính sách, giảng viên, bạn hữu, gia đình) có liên quan của sinh viên trong một khoa tại một trường đại học phía Nam. Phần tiếp theo của bài viết là cơ sở lý thuyết về hành vi không trung thực, thiết kế nghiên cứu và kết quả nghiên cứu. Cuối cùng là một số kết luận và kiến nghị.

\section{Câu hỏi nghiên cứu và khung nghiên cứu}

Trong các định nghĩa liêm chính học thuật, có lẽ định nghĩa của ICAI là đầy đủ, toàn diện nhất. Liêm chính học thuật là sự cam kết đối với 5 giá trị cơ bản: trung thực (honesty), tin cậy (trust), công bằng (fairness), tôn trọng (respect) và trách nhiệm (responsibility). Hơn 80 tổ chức học thuật (đại học, cao đẳng, trung tâm, học viện) tuyên bố ủng hộ 05 giá trị cơ bản này. Liêm chính học thuật được một số trường đại học tại Việt Nam định nghĩa là cách hành xử ngay thẳng, trung thực và trong sạch trong hoạt động học thuật như học tập, giảng dạy, nghiên cứu và các hoạt động sáng tác, sáng tạo khác (Học viện Ngân hàng, 2019; Trường Đại học Bách Khoa-ĐH Đà Nẵng, 2017; Trường Đại học Hoa Sen, 2013). Định nghĩa này gọn gàng, mang tính ứng dụng nhiều hơn trong việc định hướng đến các hành vi không trung thực học thuật hay không trung thực học thuật.

Liêm chính học thuật rất quan trọng, nhất là đối với trường đại học, vì là nhân tố chính giúp sinh viên trở thành một người trung thực và được người khác tín nhiệm. Không chỉ ở nhà trường mà cả sau này, sau khi tốt nghiệp, thành một thành viên trong tổ chức, trong xã hội, liêm chính là phẩm chất để cộng đồng đặt niềm tin vào cơ sở đào tạo hay nghiên cứu trong sử dụng nhân lực, tiếp thu tri thức. Liêm chính học thuật là cơ sở để mọi thành viên phát triển các ý tưởng, sáng kiến mới (Bauer College of Business, 2020; Western Sydney University, 2020).

Không trung thực học thuật (academic dishonesty) được xem là những hành vi vi phạm liêm chính học thuật bởi trung thực là giá trị hàng đầu trong 5 giá trị của liêm chính học thuật. Các hành vi được định nghĩa là không trung thực học thuật trong các quy định, quy chế của trường đại học và một số nghiên cứu bao gồm: gian lận (cheating), bịa đặt (frabication), đạo văn (plagiarism), hỗ trợ không trung thực (facilitating academic behavior), thông đồng (collusion), hối lộ hay đe dọa (bribes, treats) (Học viện Ngân hàng, 2019; Trường Đại học Bách Khoa-ĐH Đà Nẵng, 2017; Trường Đại học Hoa Sen, 2013; Vu, 2018).

Nghiên cứu thực nghiệm về liêm chính cũng như liêm chính học thuật ở Việt Nam còn rất ít, dưới đây là các nghiên cứu tìm được. Nghiên cứu của U. T. Tran, Huynh và Nguyen (2016) là một nghiên cứu thực nghiệm hiếm hoi được thực hiện ở một trường đại học nhằm đánh giá mức độ phổ biến và nghiêm trọng của tình trạng đạo văn của sinh viên khối Kinh tế. Nghiên cứu này sử dụng phần mềm Turnitin để đo lường chỉ số tương đồng (similiarity index) (tính bằng \%) của một bài viết đối chiếu với một bài viết khác nhưng không dẫn nguồn. Dữ liệu là 252 bài báo cáo thực tập tốt nghiệp (2013-2014) của nhiều ngành. Kết quả cho thấy đạo văn là phổ biến, chỉ số tương đồng trung bình là 47,5\% (max: $95 \%$, min: $2 \%$ ), mức báo động đỏ (chỉ số tương đồng>75\%) là $9,9 \%$ bài báo cáo, tập trung trong khoảng $25 \%-49 \%$ là hơn một nửa số bái báo cáo. Nếu chỉ số tương đồng chấp nhận được là $20 \%$ thì chỉ $4 \%$ bài báo cáo đạt yêu cầu. Thứ hai, không có sự khác biệt chỉ số tương đồng trung bình theo ngành, giới và chương trình đào tạo.

Nghiên cứu này đánh giá liêm chính học thuật của sinh viên qua nhận thức về hành vi không trung thực học thuật và mức độ thường xuyên thực hiện các hành vi này. Các câu hỏi nghiên cứu đặt ra là:

(1) Nhận thức đạo đức của sinh viên đối với các hành vi không trung thực học thuật như thế nào?

(2) Với mức nhận thức đó, sinh viên đã thực hiện các hành vi này ở mức độ nào? 


\section{(3) Các yếu tố nào tác động đến hành vi này?}

Theo mô hình tương tác của việc ra quyết định đạo đức của tổ chức do Trevino (1986) và kết quả các nghiên cứu trước, đặc biệt là tổng kết của (McCabe et al., 2001a), nhận thức về liêm chính trong học thuật và hành vi không trung thực học thuật được mô tả như Hình 1. Mối quan hệ chủ yếu của mô hình này là mối quan hệ từ nhận thức mức độ nghiêm trọng dẫn đến hành vi không trung thực của người học trong học thuật như đạo văn, gian lận, bịa đặt hay giúp đỡ người khác không đúng đắn. Bên cạnh đó, môi trường học thuật và các yếu tố cá nhân cũng được cho là có ảnh hưởng đến mức độ tác động của nhận thức lên hành vi không trung thực học thuật. Nghiên cứu này được thực hiện theo khung nghiên cứu trong Hình 1 dưới đây.

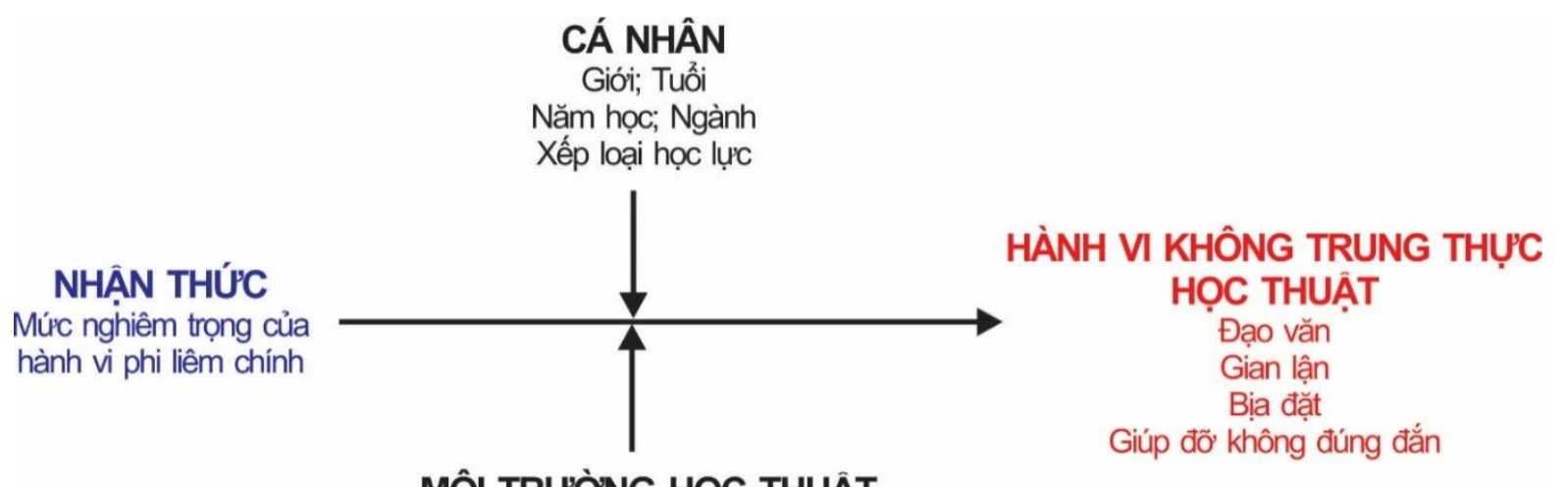

\section{MÔI TRƯỜNG HỌC THUẬT}

Chính sách liêm chính, chống gian lận :

Thái độ, hành vi của bạn hữu về liêm chính

Thái độ, hành vi của giảng viên về liêm chính

Hình 1. Ảnh hưởng của môi trường học thuật và nhận thức đến hành vi không trung thực học thuật

Nghiên cứu này nhằm phân tích và đánh giá liêm chính học thuật của sinh viên nên chỉ quan tâm đến môi trường học thuật liên quan đến liêm chính học thuật. Môi trường học thuật, theo đó, bao gồm: các quy định liên quan đến liêm chính học thuật; sự nghiêm khắc trong xử lý hành vi không trung thực học thuật từ giảng viên và trong các quy định, chính sách liên quan; mức độ diễn ra hành vi không trung thực học thuật; sự tiếp cận các quy định, chính sách liên quan đến liêm chính học thuật. Các thành phần này đã được mô tả trong nghiên cứu của McCabe (2005). Khái niệm này cũng được nhắc đến nhiều trong các nghiên cứu về liêm chính học thuật của Haines, Diekhoff, LaBeff, và Clark (1986), McCabe và Trevino (1997), McCabe và cộng sự (2001a), McCabe, Trevino, và Butterfield (2001b), McCabe, Trevino, và Butterfield (2002), McCabe (2005), McCabe, Butterfield và Trevino (2006), Macfarlane, Zhang, và Pun (2014). Có thể thấy rằng $\mathrm{McCabe}$ và các nhà nhiên nghiên cứu về liêm chính học thuật thường sử dụng khái niệm môi trường học thuật và xem yếu tố này như là một biến bối cảnh tác động đến nhận thức và hành vi liêm chính học thuật.

\section{Thiết kế nghiên cứu}

Nghiên cứu này được thực hiện tại vào tháng 12/1019. Mẫu nghiên cứu là 208 sinh viên từ năm thứ nhất đến năm tư, tập trung vào 4 ngành thuộc chính của Khoa lần lượt gọi là $\mathrm{A}, \mathrm{B}, \mathrm{C}$ và $\mathrm{D}$, cùng với 2 ngành phụ là $\mathrm{E}$ và $\mathrm{F}$. Phương thức chọn mẫu phi xác xuất được triển khai theo các ngành đào tạo một khoa trong một trường đại học phía Nam tại Việt Nam. Đây là nghiên cứu hoàn toàn ẩn danh: danh tính sinh viên tham gia khảo sát không được thu thập. Điều này có ý nghĩa quan trọng, đảm bảo số liệu được thu thập phản ánh trung thực hiện trạng liêm chính học thuật.

Mẫu được chọn thuận tiện. Cơ cấu mẫu được thể hiện trong Bảng 1. Mẫu được chọn có đủ 4 ngành chính của Khoa và sinh viên từ năm 1 đến năm 4 . Khoa hiện có 1.814 sinh viên, trong đó 
tỷ lệ sinh viên nữ là $78 \%{ }^{1}$. Tương ứng, tỷ lệ sinh viên nữ tham gia khảo sát là 165/208 (tương đương 79\%). Mẫu được chọn chiếm 11,5\% tổng thể sinh viên của Khoa.

Sinh viên tham gia khảo sát trả lời ba nhóm câu hỏi. Thứ nhất, môi trường học thuật tại Khoa được sinh viên đánh giá như thế nào. Thứ hai, sinh viên nhận thức mức độ nghiêm trọng của hành vi không trung thực học thuật ra sao. Cuối cùng là các hành vi không trung thực học thuật được thực hiện với mức độ thường xuyên như thế nào.

\section{Bảng 1}

Cơ cấu mẫu

\begin{tabular}{|c|c|c|c|c|c|c|c|c|c|c|c|c|}
\hline & \multirow{3}{*}{ NGÀNH HỌC } & \multicolumn{10}{|c|}{ NĂM HỌC } & \multirow{3}{*}{$\begin{array}{l}\text { Tổng } \\
\text { cộng }\end{array}$} \\
\hline & & \multicolumn{2}{|c|}{ Thứ nhất } & \multicolumn{2}{|c|}{ Thứ hai } & \multicolumn{2}{|c|}{ Thứ ba } & \multicolumn{2}{|c|}{ Thứ tư } & \multicolumn{2}{|c|}{ Cộng } & \\
\hline & & Nữ & Nam & Nũ & Nam & Nũ & Nam & Nũ & Nam & Nũ & Nam & \\
\hline 1 & A & 1 & 0 & 21 & 0 & 1 & 0 & 1 & 0 & 24 & 0 & 24 \\
\hline 2 & $\mathrm{~B}$ & 0 & 0 & 0 & 0 & 37 & 5 & 3 & 0 & 40 & 5 & 45 \\
\hline 3 & $\mathrm{C}$ & 1 & 0 & 0 & 0 & 0 & 0 & 25 & 14 & 26 & 14 & 40 \\
\hline 4 & $\mathrm{D}$ & 22 & 8 & 1 & 0 & 0 & 0 & 27 & 11 & 50 & 19 & 69 \\
\hline 5 & $\mathrm{E}$ & 24 & 4 & 0 & 0 & 0 & 0 & 0 & 0 & 24 & 4 & 28 \\
\hline 6 & $\mathrm{~F}$ & 1 & 1 & 0 & 0 & 0 & 0 & 0 & 0 & 1 & 1 & 2 \\
\hline \multirow{2}{*}{\multicolumn{2}{|c|}{$\begin{array}{l}\text { Cộng } \\
\text { Tổng cộng }\end{array}$}} & 49 & 13 & 22 & 0 & 38 & 5 & 56 & 25 & 165 & 43 & \\
\hline & & \multicolumn{2}{|c|}{62} & \multicolumn{2}{|c|}{22} & \multicolumn{2}{|c|}{43} & \multicolumn{2}{|c|}{81} & \multicolumn{2}{|c|}{208} & 208 \\
\hline
\end{tabular}

Nguồn: Kết quả phân tích dữ liệu của nhóm nghiên cứu

Bản hỏi được thiết kế dựa vào khảo sát liêm chính học thuật (academic integrity perception survey) của McCabe và CAI (Center of Academic Integrity) thiết kế. Bản hỏi liêm chính học thuật dành cho sinh viên đã được Canham (2008) sử dụng trong nghiên cứu của mình gồm 3 phần: (1) cảm nhận môi trường học thuật (25 mục đo), (2) hành vi gian lận: số lần thực hiện và đánh giá mức độ nghiêm trọng (42 mục đo) và (3) thông tin cá nhân (nhân khẩu học).

Thống kê mô tả được sử dụng để mô tả đặc điểm nhận thức của sinh viên về cảm nhận môi trường học thuật, số lần thực hiện hành vi không trung thực học thuật và đánh giá mức độ nghiêm trọng của những hành vi này. Các đại lượng Tau, $\mathrm{d}$, gamma được sử dụng để kiểm định mối quan hệ giữa (1) hành vi không trung thực học thuật của $S V$ và nhận thức của họ về hành vi đó, (2) hành vi và nhận thức trên với các đặc trưng cá nhân (năm đang học, xếp loại) và yếu tố môi trường (chính sách, giảng viên, cha mẹ, bạn hữu...)

\section{Kết quả nghiên cứu}

Phần này sẽ trình bày bốn nội dung chính liên quan đến nhận thức của sinh viên. Đầu tiên, nhận thức của sinh viên về môi trường học thuật được trình bày. Kế đến là mô tả nhận thức của sinh viên về một số hành vi được cho là không trung thực học thuật. Sau đó là những phân tích, đánh giá mức độ thường xuyên thực hiện các hành vi qua kết quả tự đánh giá của sinh viên. Cuối cùng là phần trình bày về kết quả kiểm định sự khác biệt mức độ nhận thức về hành vi không trung thực học thuật theo các đặc tính cá nhân của sinh viên và kiểm định sự ảnh hưởng của yếu tố cá nhân, môi trường học thuật và nhận thức đến hành vi không trung thực học thuật của sinh viên.

\footnotetext{
${ }^{1}$ Nguồn: Phòng Đào tạo
} 


\section{1. Đánh giá môi trưòng học thuật}

Môi trường học thuật liên quan đến liêm chính học thuật được mô tả và đánh giá qua cảm nhận, quan sát và nhận thức của sinh viên theo 04 khía cạnh: (1) nguồn thông tin về liêm chính học thuật đến SV (Hình 2); (2) các hành vi không liêm chính học thuật phổ biến (Bảng 2); (3) phản ứng của người chung quanh về hành vi không liêm chính học thuật (Hình 3); (4) hiệu quả của chính sách, quy định liên quan đến liêm chính học thuật (Hình 4).

Sinh viên chủ yếu biết đến các quy định liêm chính trong học thuật từ sinh hoạt tuần lễ công dân và thông qua giảng viên, đề cương chi tiết học phần. Có $64 \%$ sinh viên được khảo sát có biết về liêm chính học thuật, nhưng không nhiều, trong các buổi sinh hoạt tuần lễ công dân. Bên cạnh đó, $43 \%$ sinh viên biết được rất nhiều quy định liên quan đến liêm chính học thuật từ giảng viên và thông qua đề cương chi tiết học phần. Sinh viên thường được giảng viên hướng dẫn làm bài tập nhóm $(83 \%)$ và cách trích dẫn phù hợp (67\%). Sinh viên ít nhận được nhắc nhở của giảng viên về sự sai trái của các hành vi bịa đặt số liệu (66\%) và đạo văn, sao chép (43\%). Trợ lý học vụ, lãnh đạo Khoa và Bộ môn ít có vai trò cung cấp thông tin về liêm chính học thuật cho sinh viên.

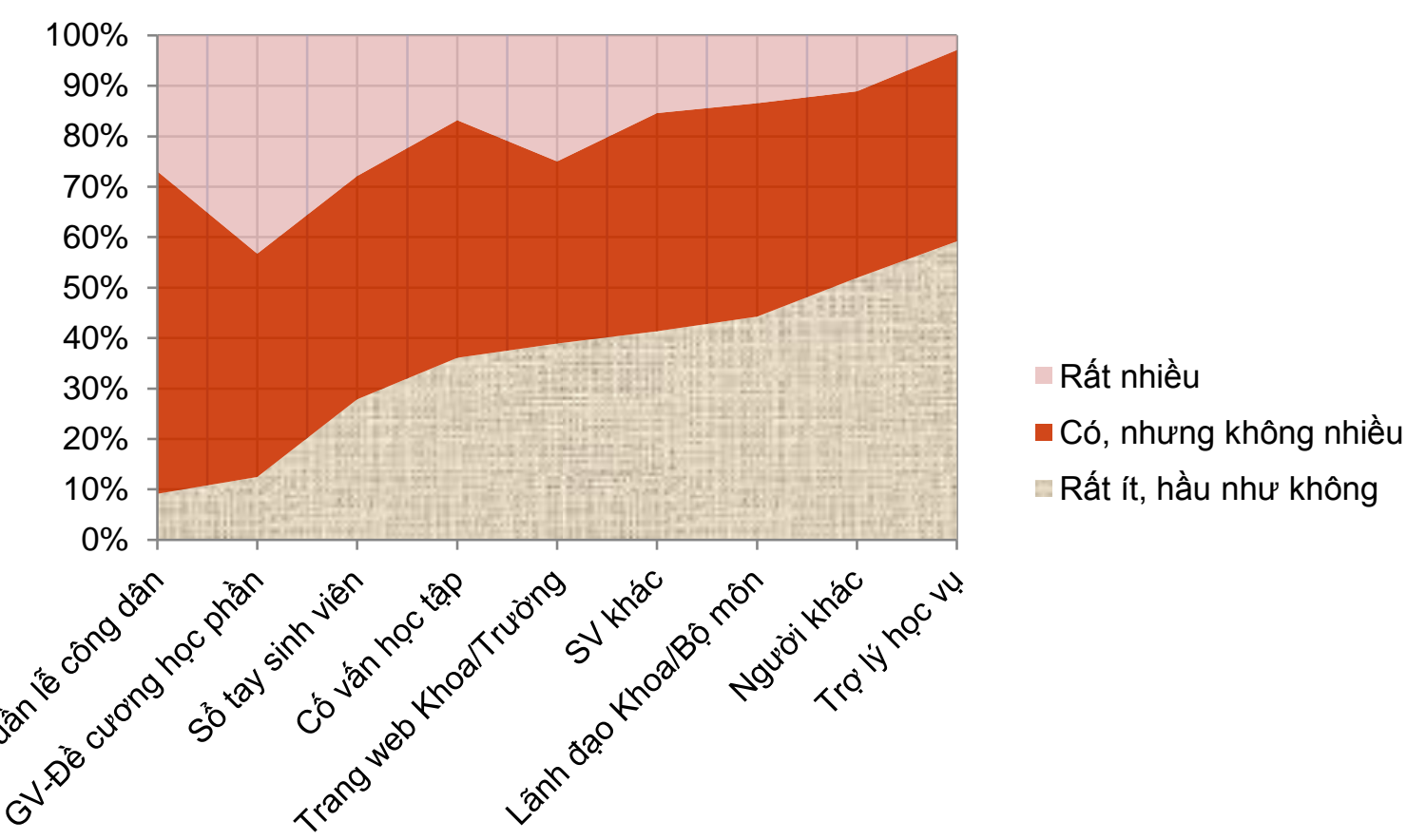

Hình 2. Nguồn thông tin về quy định liêm chính học thuật

Giảng viên và đề cương chi tiết học phần là nguồn cung cấp thông tin chủ yếu về hành xử liêm chính trong học thuật. Sinh viên nhận được hướng dẫn thường xuyên của giảng viên về cách làm bài tập nhóm $(83 \%)$, cách trích dẫn tài liệu đúng $(69 \%)$, tránh đạo văn-sao chép $(57 \%)$ và không được bịa đặt số liệu (34\%).

Sinh viên nhận thấy hành vi vi phạm liêm chính học thuật tại Khoa khá cao. Hiện tượng phổ biến nhất, thể hiện trong Bảng 2 . Từ $27 \%$ đến $46 \%$ sinh viên nhận thấy các hành vi sau được thực hiện ở mức độ thường xuyên: đạo văn, sao chép, gian lận trong kiểm tra-thi, chỉ một vài sinh viên làm bài tập cho cả nhóm. 


\section{Bảng 2}

Hành vi không trung thực học thuật phổ biến

Hành vi

Thỉnh thoảng Thường xuyên

\begin{tabular}{lll}
\hline Đạo văn, sao chép & $73 \%$ & $27 \%$ \\
Chỉ vài sinh viên làm bài tập cho cả nhóm & $54 \%$ & $46 \%$ \\
Gian lận trong thi, kiểm tra & $64 \%$ & $36 \%$ \\
\hline
\end{tabular}

Nguồn: Kết quả phân tích dữ liệu của nhóm nghiên cứu

Kết quả trong Hình 3 cho thấy phản ứng khá tiêu cực của người chung quanh trước hành vi không trung thực học thuật. Có đến $44 \%$ sinh viên cho biết bạn học không phản đối hành vi không trung thực, thêm 7\% đồng tình với gian lận trong học thuật. Điều này đồng nghĩa với không đến $50 \%$ sinh viên nhận được sự phản đối của bạn học về hành vi không trung thực học thuật. về phía cha mẹ sinh viên, $9 \%$ sinh viên không nhận được sự phản đối của cha mẹ về hành vi không trung thực học thuật của họ, cá biệt có trường hợp nhận được sự đồng tình của cha mẹ (1\%). Sự phản đối của anh em, họ hàng cũng tiêu cực. Các kết quả này cho thấy bạn bè và gia đình không phản đối mãnh liệt hành vi không trung thực học thuật.

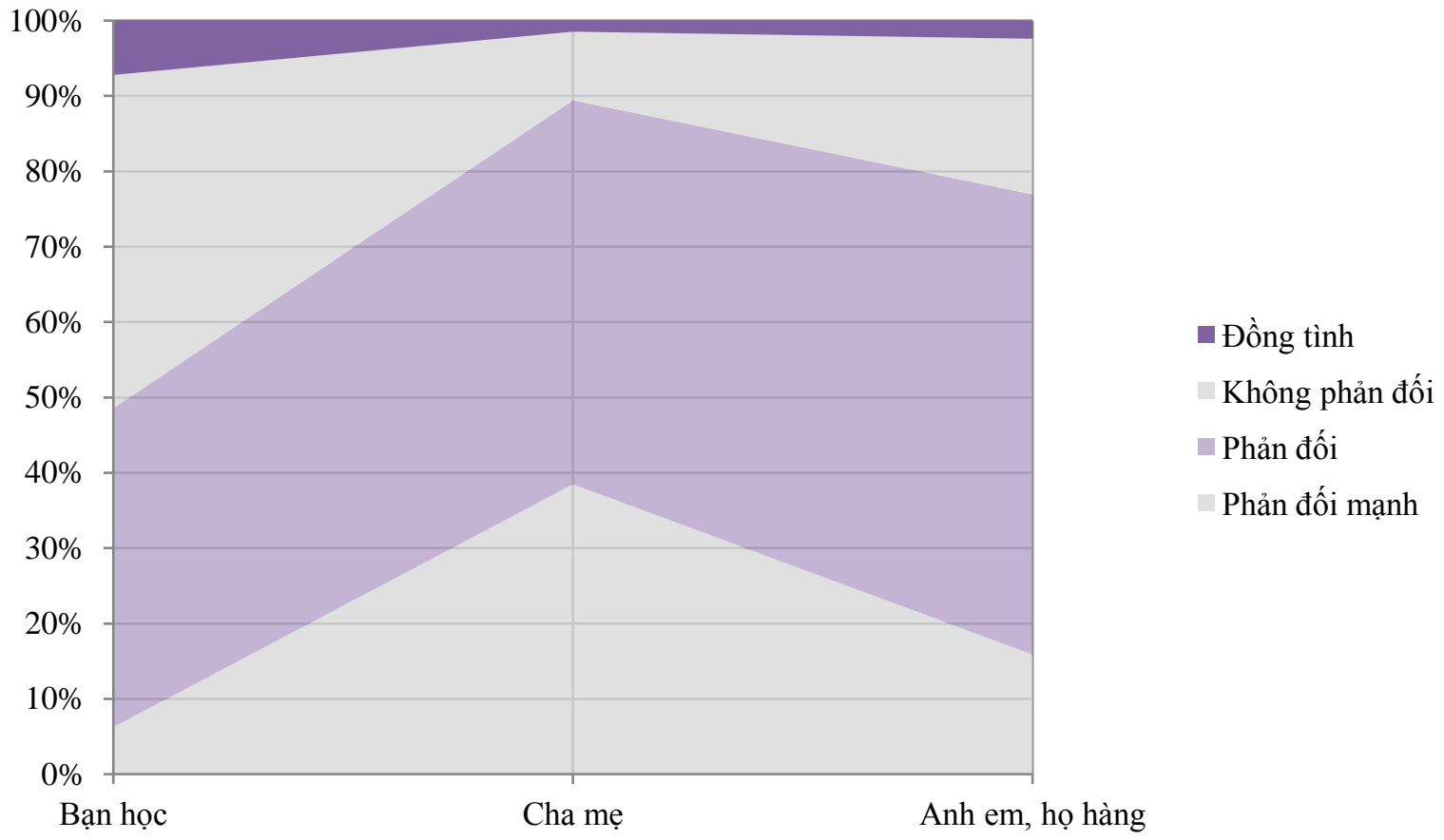

Hình 3. Phản ứng của người chung quanh với hành vi không trung thực học thuật

Tương đồng với kết quả trên, có rất ít sinh viên tố giác khi phát hiện hành vi không trung thực của người khác. Chỉ có 8 trong số 208 sinh viên tham gia khảo sát trả lời sẽ tố giác khi phát hiện gian lận, chiếm 3,8\%. Phần còn lại không có ý định tố giác.

Hình 4 mô tả nhận thức của sinh viên về các quy định, chính sách liêm chính học thuật. Kết quả khảo sát cho thấy sinh viên cho rằng quy định xử lý gian lận là nghiêm khắc, nhưng mức hiệu quả thấp. Hơn hai phần ba sinh viên đồng ý rằng mức độ nghiêm khắc trong xử lý gian lận là cao. Tuy nhiên hơn phân nửa sinh viên cho rằng mức độ hiệu quả của các quy định ở mức trung bình thấp và có đến $57 \%$ sinh viên chưa hoàn toàn ủng hộ các quy định, chính sách hiện hành về liêm chính học thuật. Có $58 \%$ sinh viên đánh giá mức độ hiệu quả của các quy định, chính sách ở mức trung bình, thấp và rất thấp. 
Theo đánh giá của $78 \%$ sinh viên, giảng viên nhận thức tốt về các quy định; theo đó, có $22 \%$ sinh viên cho rằng giảng viên có nhận thức chưa cao về quy định liêm chính học thuật. Trong khi đó, chỉ có $40 \%$ cho rằng sinh viên có nhận thức đầy đủ về các quy định liêm chính học thuật. Điều này cho thấy, sinh viên tự đánh giá rằng nhiều sinh viên và một bộ phận giảng viên chưa nhận thức đầy đủ về liêm chính học thuật.

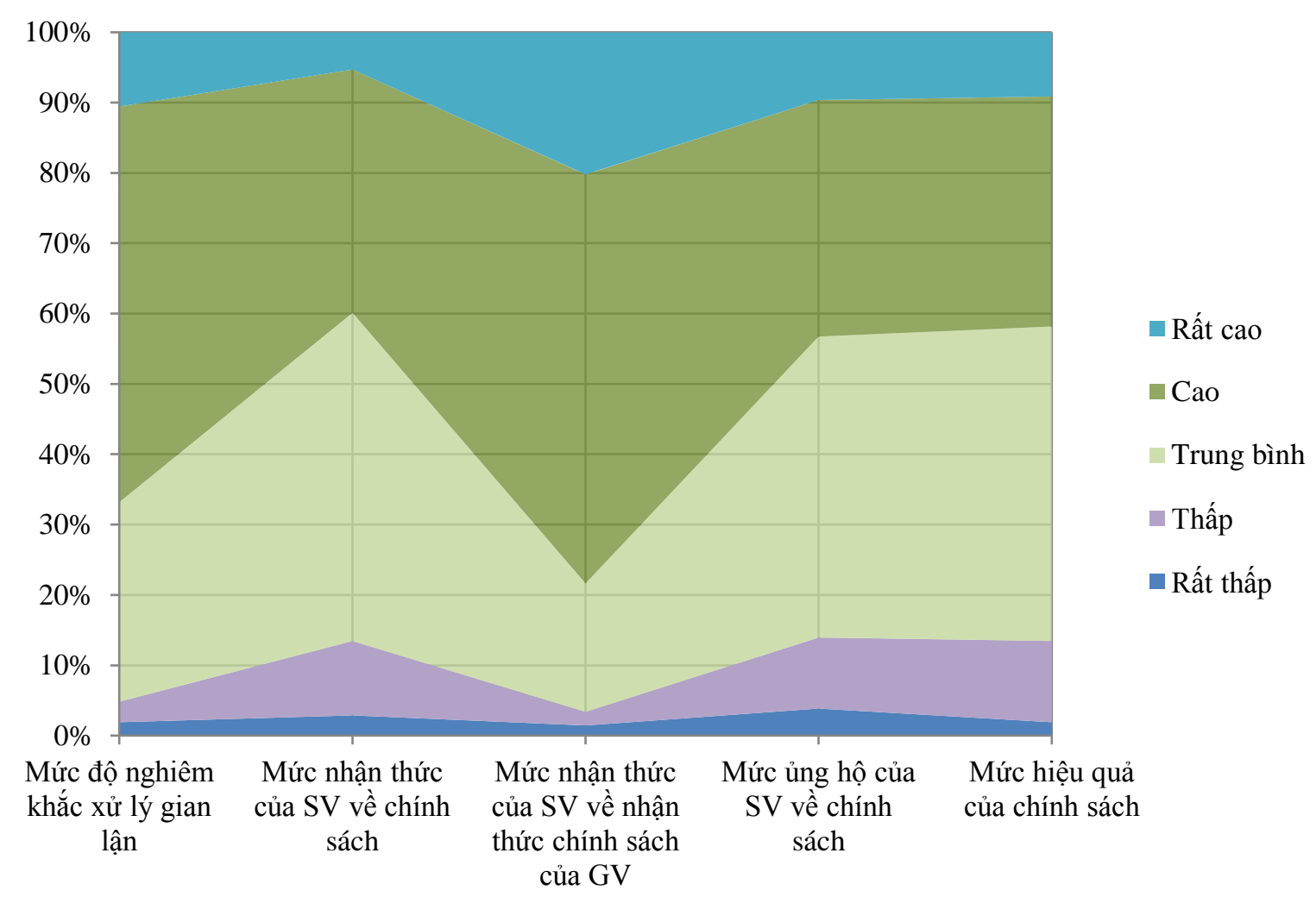

Hình 4. Nhận thức của sinh viên về chính sách liêm chính học thuật

\section{học thuật. \\ 4.2. Nhận thức của sinh viên về mức nghiêm trọng của các hành vi không trung thục}

Có tất cả 21 hành vi không trung thực học thuật thuộc 5 nhóm: gian lận, đạo văn, bịa đặt, giúp đỡ không chính đáng, thông đồng được liệt kê trong nghiên cứu (xem thêm mục 4.3). Sinh viên được hỏi ý kiến đánh giá về mức nghiêm trọng của các hành vi này theo 4 chọn lựa từ (1) không phải là gian lận, (2) không nghiêm trọng, (3) nghiêm trọng và (4) rất nghiêm trọng. Đối với một hành vi, mức đầu tiên cho thấy sinh viên không xem hành vi được hỏi là gian lận; ba mức còn lại thể hiện sinh viên cho rằng hành vi được hỏi là gian lận ở 3 mức độ khác nhau.

Nhìn chung, sinh viên cho rằng các hành vi không trung thực học thuật là không quá nghiêm trọng và có những đánh giá khác nhau đối với các hành vi khác nhau. Rất ít sinh viên cho rằng các hành vi sau đây là sai phạm ở mức độ nghiêm trọng: làm bài tập cá nhân chung (3\%), lấy bài giải, đề kiểm tra của lớp khác để chuẩn bị bài kiểm tra cho mình $(4 \%)$ và nhờ người khác làm hộ bài tập về nhà $(10 \%)$. Hơn $20 \%$ đến $30 \%$ sinh viên cho rằng ba hành vi nói trên không phải là gian lận.

Sinh viên cho rằng các hành vi sau là rất nghiêm trọng: Sử dụng thiết bị điện tử trái phép khi thi $(51 \%)$, sử dụng số liệu trong bộ nhớ thiết bị điện tử khi thi (47\%), sử dụng tài liệu viết tay trái phép khi thi (41\%) mà sinh viên đã thực hiện cùng nhận thư và mua các bài làm để nộp (35\%). Tuy nhiên, vẫn có đến từ $8 \%$ đến $10 \%$ sinh viên cho rằng các hành vi sau không phải là gian lận: 
Làm giúp, chỉ bài cho bạn khi kiểm tra, sao chép một phần bài làm của người khác, xem bài bạn khi kiểm tra, được bạn đồng ý. Kết quả này cho thấy nhận thức về hành vi liêm chính học thuật của sinh viên còn sai lệch, đáng chú ý.

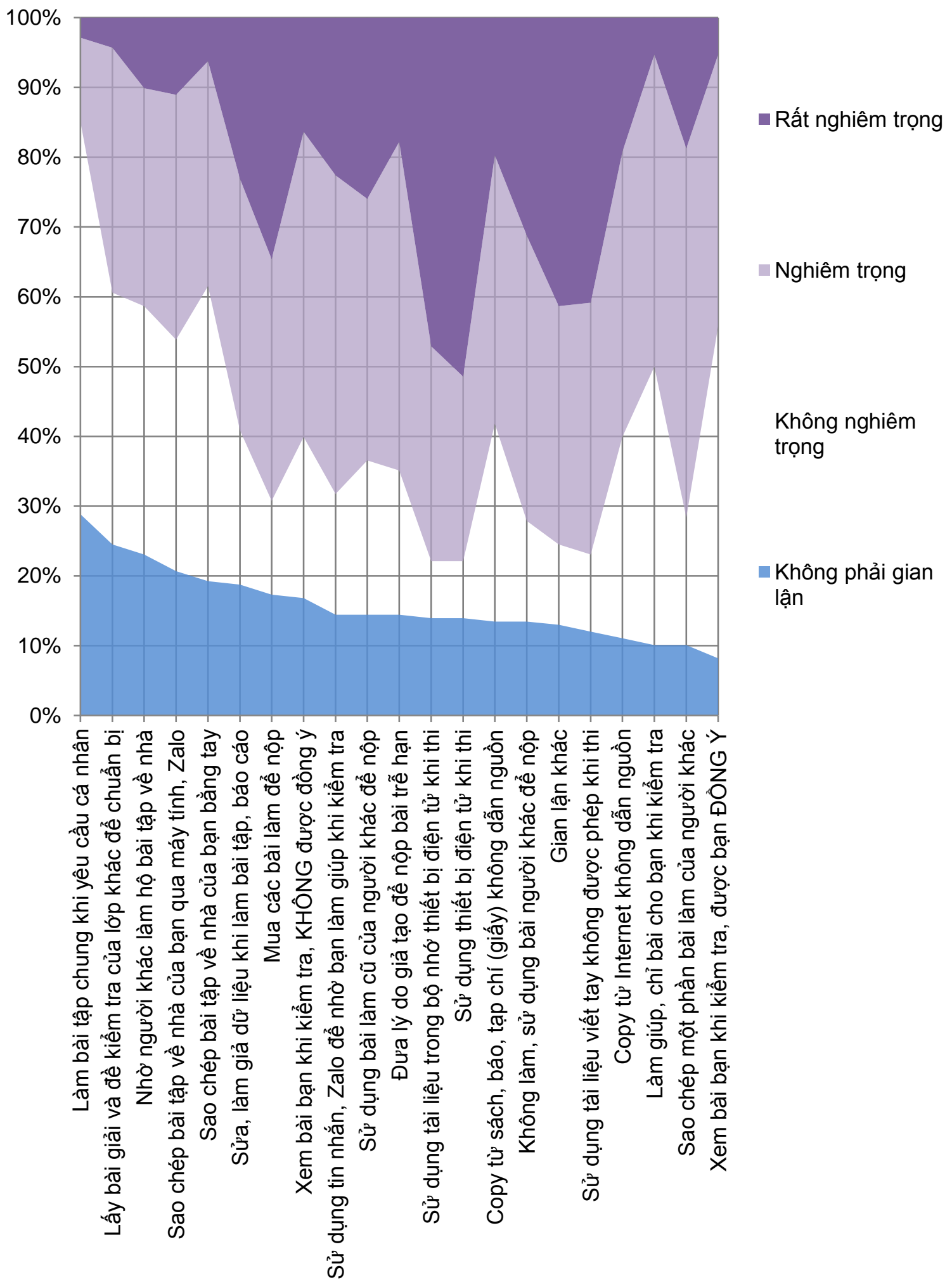

Hình 5. Nhận thức mức độ nghiêm trọng của hành vi không trung thực học thuật 


\subsection{Hiện trạng không trung thực học thuật}

Hiện trạng này được mô tả qua hồi đáp của sinh viên về số lần thực hiện một hay nhiều hành vi trong số 21 hành vi không trung thực học thuật được liệt kê trong Bảng 3.

Các hành vi vi phạm liêm chính học thuật phổ biến của sinh viên với mức độ hơn một lần là: làm bài tập cá nhân chung (72\%), làm giúp, chỉ bài cho bạn khi kiểm tra $(64 \%)$, xem bài của bạn khi kiểm tra, được sự đồng ý của bạn (58\%). Hơn một phần ba sinh viên thường xuyên mắc các lỗi sao chép từ sách báo, internet và bài của người khác. Các hành vi sinh viên ít vi phạm là mua bài làm để nộp, sử dụng số liệu trong bộ nhớ thiết bị điện tử khi thi, sử dụng thiết bị điện tử trái phép khi thi, không làm-sử dụng bài người khác để nộp. Trên $90 \%$ sinh viên chưa thực hiện các hành vi này, nhưng vẫn có một vài trường hợp đã từng thực hiện. Chi tiết về mức độ thường xảy ra hành vi không trung thực học thuật được thể hiện trong Bảng 3.

\section{Bảng 3}

Hành vi không trung thực học thuật

\begin{tabular}{|c|c|c|c|c|}
\hline STT & Hành vi & $\begin{array}{c}\text { Chưa bao } \\
\text { giờ }\end{array}$ & Một lần & $\begin{array}{c}\text { Hơn một } \\
\text { lần }\end{array}$ \\
\hline 1 & Làm bài tập chung khi yêu cầu cá nhân & $14 \%$ & $13 \%$ & $72 \%$ \\
\hline 2 & Làm giúp, chỉ bài cho bạn khi kiểm tra & $17 \%$ & $19 \%$ & $64 \%$ \\
\hline 3 & Xem bài bạn khi kiểm tra, được bạn ĐỒNG Ý & $23 \%$ & $20 \%$ & $58 \%$ \\
\hline 4 & Copy từ Internet không dẫn nguồn & $46 \%$ & $20 \%$ & $35 \%$ \\
\hline 5 & Copy từ sách, báo, tạp chí (giấy) không dẫn nguồn & $47 \%$ & $23 \%$ & $30 \%$ \\
\hline 6 & Lấy bài giải và đề kiểm tra của lớp khác để chuẩn bị & $49 \%$ & $15 \%$ & $36 \%$ \\
\hline 7 & Sao chép bài tập về nhà của bạn bằng tay & $52 \%$ & $20 \%$ & $28 \%$ \\
\hline 8 & Sao chép một phần bài làm của người khác & $54 \%$ & $29 \%$ & $17 \%$ \\
\hline 9 & Sao chép bài tập về nhà của bạn qua máy tính, Zalo & $65 \%$ & $14 \%$ & $21 \%$ \\
\hline 10 & Sửa, làm giả dữ liệu khi làm bài tập, báo cáo & $70 \%$ & $18 \%$ & $12 \%$ \\
\hline 11 & Nhờ người khác làm hộ bài tập về nhà & $74 \%$ & $16 \%$ & $11 \%$ \\
\hline 12 & Sử dụng bài làm cũ của người khác để nộp & $75 \%$ & $15 \%$ & $11 \%$ \\
\hline 13 & Sử dụng tin nhắn, Zalo để nhờ bạn làm giúp khi kiểm tra & $81 \%$ & $11 \%$ & $8 \%$ \\
\hline 14 & Đưa lý do giả tạo để nộp bài trễ hạn & $82 \%$ & $14 \%$ & $4 \%$ \\
\hline 15 & Sử dụng tài liệu viết tay không được phép khi thi & $83 \%$ & $10 \%$ & $7 \%$ \\
\hline 16 & Gian lận khác & $84 \%$ & $9 \%$ & $8 \%$ \\
\hline 17 & Xem bài bạn khi kiểm tra, KHÔNG được đồng ý & $85 \%$ & $8 \%$ & $8 \%$ \\
\hline 18 & Không làm, sử dụng bài người khác để nộp & $92 \%$ & $6 \%$ & $2 \%$ \\
\hline 19 & Sử dụng thiết bị điện tử khi thi & $93 \%$ & $5 \%$ & $2 \%$ \\
\hline 20 & Sử dụng tài liệu trong bộ nhớ thiết bị điện tử khi thi & $94 \%$ & $6 \%$ & $0 \%$ \\
\hline 21 & Mua các bài làm để nộp & $95 \%$ & $2 \%$ & $2 \%$ \\
\hline
\end{tabular}

Nguồn: Kết quả phân tích dữ liệu của nhóm nghiên cứu 


\subsection{Một số yếu tố tác động đến hành vi không trung thục học thuật}

Phần này trình bày sự chi phối của các yếu tố cá nhân (năm học, học lực...) và môi trường học thuật (thái độ của cha mẹ, bạn hữu, chính sách, quy định và hiệu quả của chúng) đến nhận thức và hành vi của sinh viên về không trung thực học thuật, được trình bày trong Phụ lục $\mathrm{A}$.

Xếp loại học lực có ảnh hưởng đến nhận thức mức độ nghiêm trọng của những hành vi không trung thực học thực và kết quả thực hiện một số hành vi này. Những sinh viên có học lực tốt hơn nhận ra rằng một số hành vi có mức độ nghiêm trọng hơn so với cảm nhận của những sinh viên có học lực kém hơn. Các sinh viên có học lực tốt hơn cũng ít thực hiện các hành vi không trung thực học thuật so với các sinh viên có học lực kém hơn. Kết quả này được tìm thấy đối với một số hành vi trong số 21 hành vi được nghiên cứu, lần lượt là $6 / 21$ đối với nhận thức mức độ nghiêm trọng và $5 / 21$ đối với hành vi vi phạm. Dù không xảy ra với tất cả các hành vi, cũng có thể nhận thấy rằng những sinh viên có học lực tốt hơn thì có ý thức cao hơn đối với những hành vi vi phạm liêm chính học thuật.

Về số năm học tập tại trường, sinh viên ở những năm sau có xu hướng thực hiện hành vi không trung thực học thuật nhiều hơn. Tình trạng sao chép diễn ra nhiều hơn đối với sinh viên năm 3 và năm tư. Những sinh viên năm cuối nhận ra mình mắc sai sót về trích dẫn nhiều hơn. Chỉ riêng trường hợp bịa đặt số liệu nhận thấy mình ít mắc sai lầm hơn sinh viên năm nhất và năm tư.

Có nhiều mối tương quan trái chiều giữa hành vi vi phạm trung thực học thuật với sự nghiêm khắc trong xử lý gian lận (3 hành vi) và mức hiệu quả chính sách liên quan đến gian lận học thuật (4 hành vi). Điều này có nghĩa là, khi sinh viên nhận thức được sự nghiêm khắc trong xử lý gian lận học thuật và tính hiệu quả của chính sách học thuật, sinh viên sẽ ít vi phạm học thuật. Ngoài ra, khi sinh viên nhận thấy giảng viên nghiêm khắc với gian lận học thuật, sinh viên có xu hướng nhờ người khác làm hộ bài tập về nhà. Sinh viên cho rằng giảng viên khó phát hiện nếu nhờ người khác làm bài so với sao chép bài của người khác. Sinh viên có thể thực hiện hành vi này để đối phó với những giảng viên mà sinh viên cho là nghiêm khắc trong học thuật. Tương tự như vậy, sinh viên sẽ cho rằng lấy bài giải và đề kiểm tra của lớp khác để chuẩn bị cho bài kiểm tra sắp tới là không nghiêm trọng khi chính sách liên quan đến học thuật có hiệu quả. Trong các trường hợp còn lại, nhận thức về hành vi vi phạm học thuật của sinh viên không bị ảnh hưởng với sự nghiêm khắc của chính sách và của giảng viên. Kết quả này cho thấy rằng, chủ yếu là hành vi vi phạm học thuật của sinh viên bị tác động bởi sự nghiêm khắc và tính hiệu quả của quy định, chính sách về học thuật. Chính sách chủ yếu làm thay đổi hành vi, không ảnh hưởng đáng kể nhận thức mức nghiêm trọng của hành vi.

Phản ứng của bạn bè và cha mẹ có ảnh hưởng khá lớn đến nhận thức mức độ nghiêm trọng của hành vi vi phạm liêm chính học thuật và số lần thực hiện các hành vi này. Kết quả cho thấy có 9 mối tương quan trái chiều giữa hành vi vi phạm liêm chính học thuật và phản ứng của của bạn học. Theo đó, sự phản đối của bạn học có tác động làm giảm mức độ thường xuyên có nhiều hành vi vi phạm liêm chính học thuật. Trong khi đó, nhận thức về mức độ nghiêm trọng của các hành vi này chịu sự tác động của phản ứng từ cha mẹ sinh viên. Rất tiếc là, như kết quả nghiên cứu đã trình bày, mức độ phản đối của cha mẹ và bạn bè đối với hành vi vi phạm liêm chính học thuật không cao.

Tương quan thuận chiều giữa nhận thức mức độ nghiêm trọng của hành vi vi phạm liêm chính học thuật và số lần vi phạm được tìm thấy trong 10 hành vi (xem Phụ lục $\mathrm{A}$ ). Điều này khẳng định mối quan hệ giữa nhận thức và hành vi trong bối cảnh liêm chính học thuật. Khi sinh viên không nhận thấy mức độ nghiêm trọng của hành vi vi phạm liêm chính học thuật, họ có xu hướng thực hiện hành vi này nhiều hơn. 


\section{Thảo luận và kết luận}

\subsection{Các kết quả chính}

Kết quả nghiên cứu cho thấy nhận thức về liêm chính học thuật của sinh viên còn chưa đầy đủ. Một số hành vi không trung thực học thuật được không ít sinh viên xem là không nghiêm trọng; thậm chí có từ 8 đến $10 \%$ sinh viên không xem các hành vi sau là hành vi không trung thực học thuật: làm giúp, chỉ bài cho bạn khi kiểm tra, sao chép một phần bài làm của người khác, xem bài bạn khi kiểm tra, được bạn đồng ý. Nhận thức này có tương quan với mức độ thường xuyên thực hiện hành vi không trung thực học thuật: khi sinh viên nhận thức một hành vi là không hoặc ít nghiêm trọng sẽ thực hiện các hành vi này với mức độ thường xuyên hơn.

Kết quả nghiên cứu cũng cho thấy môi trường học thuật có tác động đến nhận thức và hành vi của sinh viên về liêm chính học thuật. Môi trường học thuật cần được cải thiện qua đánh giá của sinh viên về sự nghiêm khắc trong xử lý hành vi không trung thực học thuật từ giảng viên và trong các quy định, chính sách liên quan, sự tiếp cận các quy định, chính sách liên quan đến liêm chính học thuật, phản ứng của gia đình và bạn bè của sinh viên về hành vi không trung thực học thuật không cao. Nguồn thông tin liên quan đến quy định liêm chính học thuật dành cho sinh viên chủ yếu là từ sinh hoạt tuần lễ công dân và trực tiếp từ giảng viên. Cơ sở giáo dục đại học cần chú trọng xây dựng và thực thi các chính sách, quy định liên quan đến liêm chính học thuật từ giảng viên đến sinh viên.

\subsection{Thảo luận}

Nghiên cứu này về liêm chính học thuật của sinh viên đại học gợi mở vài vấn đề liên quan đến kiến tạo liêm chính trong học thuật tại trường đại học.

Việc tạo lập môi trường cho sự phát triển liêm chính học thuật cho giảng viên, sinh viên cũng là góp phần giáo dục đạo đức cho sinh viên. Có thể nói như vậy vì liêm chính học thuật là một khía cạnh đạo đức của của sinh viên. Quy định, chính sách hiện hành về xử lý gian lận được sinh viên cho cần nghiêm khắc và hiệu quả để ngăn chặn hành vi vi phạm liêm chính học thuật. Xã hội, gia đình và bạn cùng học đồng góp phần ảnh hưởng đến nhận thức và hành vi của sinh viên. Trong đó, vai trò của gia đình được đề cao trong giáo dục nhận thức của người học về liêm chính. Như một sự lan tỏa trong cộng đồng, bạn đồng học có ảnh hưởng đến hành vi vi phạm liêm chính trong học thuật.

Giảng viên đóng vai trò quan trọng trong xây dựng môi trường học thuật liêm chính. Trước hết giảng viên là người cung cấp thông tin, quy định liên quan đến liêm chính học thuật qua đề cương chi tiết học phần và trong quá trình giảng dạy. Kết quả nghiên cứu cho thấy nhận thức của sinh viên về sự quan tâm của giảng viên đến liêm chính học thuật có tác động đến nhận thức mức độ nghiêm trọng của hành vi phạm liêm chính học thuật và việc thực hiện các hành vi này. Nhận thức của sinh viên quyết định hành vi của sinh viên. Cho nên, một trong những vai trò của giảng viên là nâng cao nhận thức của sinh viên về liêm chính học thuật.

Cần thực hiện những nghiên cứu đầy đủ và chi tiết hơn để xây dựng và phát triển môi trường học thuật ở Trường. Hiệu quả của các chính sánh, quy định liên quan đến liêm chính học thuật được sinh viên cho rằng thấp. Đây là cơ sở ban đầu để nhà Trường xem xét lại những quy định, chính sách hiện hành về liêm chính học thuật. Cần có những nghiên cứu đánh giá môi trường học thuật, nhận thức về liêm chính học thuật và các hành vi không trung thực học thuật từ góc nhìn của cả giảng viên và sinh viên. Kết quả của những nghiên cứu này sẽ là cơ sở thực tiễn để đề xuất quy định, chính sách liên quan đến môi trường học thuật.

Kết quả khảo sát cho thấy mức độ phản ứng của gia đình và bạn bè về hành vi không trung 
thực học thuật không cao. Rất ít $(3,8 \%)$ sinh viên tham gia khảo sát trả lời sẽ tố giác khi phát hiện gian lận; phần còn lại không có ý định tố giác. Đây là một hiện tượng đáng được nghiên cứu thêm trong các nghiên cứu sau. Sinh viên tốt nghiệp sẽ trở thành phụ huynh sau này. Có thể nói rằng, các trường đại học có vai trò quan trọng trong việc tác động đến nhận thức xã hội về liêm chính học thuật nói riêng và liêm chính nói chung. Đây là vai trò và trách nhiệm không nhỏ đối với cộng đồng của trường đại học xét ở khía cạnh giáo dục đạo đức xã hội.

Kết quả nghiên cứu cho thấy tình trạng sao chép diễn ra nhiều hơn đối với sinh viên năm 3 và năm tư, trong khi những sinh viên năm cuối nhận ra mình mắc sai sót về trích dẫn nhiều hơn. Phải chăng (1) càng về sau sinh viên mới nhận ra mình mắc phải sai lầm, trong khi nhưng năm đầu, sinh viên chưa nhận ra hành vi của mình là sai; hay (2) do áp lực làm bài tập, kiểm tra và thi cử càng nhiều ở những năm học cuối khiến sinh viên thực hiện nhưng hành vi không trung thực. Cần một nghiên cứu khác, với kỹ thuật phỏng vấn sâu chẳng hạn, để làm rõ vấn đề này.

\subsection{Hạn chế của nghiên cúu}

Nghiên cứu được thực hiện trên phạm vi hẹp. Mẫu được chọn là sinh viên của của một khoa đào tạo của một trường đại học. Nghiên cứu cần được thực hiện trên phạm vi rộng hơn: (1) nhiều khoa đào tạo của một trường đại học; (2) nhiều trường đại học.

\section{Tài liệu tham khảo}

Akakandelwa, A., Jain, P., \& Wamundila, S. (2013). Academic dishonesty: A comparative study of students of library and information science in Botswana and Zambia. Journal of Information Ethics, 22(2), 137-150.

Amirta, T. (2014). A map of scientific plagiarism around the world. Retrieved December 22, 2019, from https://www.fastcompany.com/3039921/a-map-of-scientific-plagiarism-around-theworld

Bauer College of Business. (2020). Bauer academic honesty. Retrieved April 4, 2020, from https://www.bauer.uh.edu/current/academic-honesty.php

Bohannon, J. (2017). Study of massive preprint archive hints at the geography of plagiarism. Retrieved December 31, 2019, from https://www.sciencemag.org/news/2014/12/studymassive-preprint-archive-hints-geography-plagiarism

Canham, A. A. (2008). Evaluating academic integrity and outreach efforts: Changes in perceptions over a three-year period. Lubbock, TX: Texas Tech University.

Haines, V. J., Diekhoff, G. M., LaBeff, E. E., \& Clark, R. E. (1986). College cheating: Immaturity, lack of commitment, and the neutralizing attitude. Research in Higher Education, 25(4), 342-354.

Hien Le (2018). Nhức nhối vấn nạn học hộ, thi hộ trên giảng đường đại học [It hurts the problem of student learning, exam for students in the university lecture hall]. Retrieved December 30, 2019, from https://giaoduc.net.vn/tieu-diem/nhuc-nhoi-van-nan-hoc-ho-thi-ho-trengiang-duong-dai-hoc-post189045.gd

Học viện Ngân hàng. (2019). Quyết định số 119/QĐ-HVNH. Ngày 20/02/2019. Ban hành Quy định liêm chính học thuật của Học viện Ngân hàng [Decision No. 119 / QD-HVNH. February 20, 2019. The bank academy's academic integrity policy has been issued]. Retrieved February 15, 2020, from http://hvnh.edu.vn/pdt/vi/qcdt-quy-dinh-cua-hvnh/quydinh-liem-chinh-hoc-thuat-cua-hoc-vien-ngan-hang-143.html 
Kien Van (2019). Phó Giáo su Trần Thị Kim Oanh có đạo văn không? [Is associate professor Tran Thi Kim Oanh plagiarism?]. Retrieved December 17, 2019, from https://giaoduc.net.vn/giao-duc-24h/pho-giao-su-tran-thi-kim-oanh-co-dao-van-khongpost205540.gd

Macfarlane, B., Zhang, J., \& Pun, A. (2014). Academic integrity: A review of the literature. Studies in Higher Education, 39(2), 339-358.

McCabe, D. L, Butterfield, K. D., \& Trevino, L. K. (2006). Academic dishonesty in graduate business programs: Prevalence, causes, and proposed action. Academy of Management Learning \& Education, 5(3), 294-305.

McCabe, D. L, Trevino, L. K., \& Butterfield, K. D. (2002). Honor codes and other contextual influences on academic integrity: A replication and extension to modified honor code settings. Research in Higher Education, 43(3), 357-378.

McCabe, D. L. (2005). It takes a village: Academic dishonesty \& educational opportunity. Liberal Education, 91(3), 26-31.

McCabe, D. L., \& Trevino, L. K. (1997). Individual and contextual influences on academic dishonesty: A multicampus investigation. Research in Higher Education, 38(3), 379-396.

McCabe, D. L., Trevino, L. K., \& Butterfield, K. D. (2001a). Cheating in academic institutions: A decade of research. Ethics \& Behavior, 11(3), 219-232.

McCabe, D. L., Trevino, L. K., \& Butterfield, K. D. (2001b). Dishonesty in academic environments: The influence of peer reporting requirements. The Journal of Higher Education, 72(1), 29-45.

Nghiem Hue (2018). Kết luận nóng 'nghi án' đạo văn luận án tiến sĩ [Hot conclusion 'suspicion' plagiarism thesis]. Retrieved December 17, 2019, from https://www.tienphong.vn/giaoduc/ket-luan-nong-nghi-an-dao-van-luan-an-tien-si-1244781.tpo

Ngoc Mai (2018). "Nở rộ" dịch vụ học thuê: Chất lương nhũng tấm bằng sẽ về đâu? ["Bloom" school rental service: Where will the diploma quality go?]. Retrieved December 30, 2019, from https://baophapluat.vn/giao-duc/no-ro-dich-vu-hoc-thue-chat-luong-nhung-tam-bangse-ve-dau-423389.html

Ngoc Quang (2019). Phó Giáo su-Tiến sĩ Hoàng Xuân Quế chính thức thắng kiện [Associate Professor-Dr. Hoang Xuan Que has officially won the case]. Retrieved December 20, 2019, from https://giaoduc.net.vn/giao-duc-24h/pho-giao-sutien-si-hoang-xuan-que-chinh-thucthang-kien-post197196.gd

Nguyen Thao (2018). Các trường “mon men" sư dụng phần mềm phát hiện đạo văn [The "monstrous" fields use plagiarism software]. Retrieved December 20, 2019, from https://vietnamnet.vn/vn/giao-duc/nguoi-thay/cac-truong-mon-men-su-dung-phan-memphat-hien-dao-van-435307.html

Nguyen, A. M. (2019a). Báo động tình trạng liêm chính học thuật theo kiểu "không hương dẫn, vẫn... có quyền đứng tên chung" [Alerting academic integrity in the "no guidance, still ... right of common name"]. Retrieved December 17, 2019, from http://baophunuthudo.vn/article/29304/176/bao-dong-tinh-trang-liem-chinh-hoc-thuattheo-kieu-khong-huong-dan-van-co-quyen-dung-ten-chung 
Nguyen, A. M. (2019b). Trở lại vụ ông Nguyễn Đức Tồn đạo văn vẫn được phong Giáo su: Vấn đề liêm chính khoa hoc chư không phải tranh chấp bản quyền, chia nhuận bút! [Back to the case of Mr. Nguyen Duc Ton plagiarism was still promoted to Professor: Scientific integrity, not dispute over copyright and royalties!]. Retrieved December 19, 2019, from http://baophunuthudo.vn/article/29233/176/van-de-liem-chinh-khoa-hoc-chu-khong-phaitranh-chap-ban-quyen-chia-nhuan-but

Nonis, S., \& Swift, C. O. (2001). An examination of the relationship between academic dishonesty and workplace dishonesty: A multicampus investigation. Journal of Education for Business, 77(2), 69-77.

Phuong Anh (2010). Liêm chính trong học thuật [Academic integrity]. Retrieved December 17, 2019, from http://tiasang.com.vn/-khoa-hoc-cong-nghe/liem-chinh-trong-hoc-thuat-3193

Quang Minh (2019). Vụ ông Hoàng Xuân Quế bị tố đạo văn: Bộ Giáo dục và Đào tạo khẳng định đã kháng cáo đúng hạn [Mr. Hoang Xuan Que's plagiarism case: The Ministry of Education and Training confirmed that he had appealed on time]. Retrieved December 17, 2019, from https://baophapluat.vn/thoi-su/vu-ong-hoang-xuan-que-bi-to-dao-van-bo-giao-duc-va-daotao-khang-dinh-da-khang-cao-dung-han-446788.html

Tầm nhìn. (2019). Bà Vũ Thị Sao Chi vi phạm liêm chính học thuật nhu thế nào? [How did Ms. $\mathrm{Vu}$ Thi Sao Chi violate academic integrity?]. Retrieved December 17, 2019, from https://tamnhin.net.vn/ba-vu-thi-sao-chi-vi-pham-liem-chinh-hoc-thuat-nhu-the-nao75263.html

Thu Quynh (2019). Đạo đức học thuật trong KHXH\&NV và nhũng khoảng trống [Academic ethics in social sciences \& humanities and gaps]. Retrieved December 17, 2019, from http://tiasang.com.vn/-quan-ly-khoa-hoc/Dao-duc-hoc-thuat-trong-KHXHNV-va-nhungkhoang-trong-14104

Tran, U. T., Huynh, T., \& Nguyen, H. T. T. (2016). Vấn đề liêm chính học thuật trong sự nghiệp "trồng người" [ Academic integrity in the career of "planting people"]. Tạp chí Khoa hoc ĐH Su Pham TP. HCM, 2(80), 54-61.

Tran, V. D. (2019a). Gian lận thi cư: "Hãy rưa tai để nghe lời nói thật" [Cheating on exams: "Wash your ears to hear the truth"]. Retrieved December 17, 2019, from https://dantri.com.vn/giao-duc-khuyen-hoc/gian-lan-thi-cu-hay-rua-tai-de-nghe-loi-noithat-20191214133533124.htm

Tran, V. D. (2019b). Gian lận thi cư: Lo âu về phẩm giá của thế hệ tương lai, về tiền đồ dân tộc! [Exam fraud: Worried about the dignity of the future generation, about national money!]. Retrieved December 17, 2019, from https://dantri.com.vn/giao-duc-khuyen-hoc/gian-lanthi-cu-lo-au-ve-pham-gia-cua-the-he-tuong-lai-ve-tien-do-dan-toc20191213103926031.htm

Trevino, L. K. (1986). Ethical decision making in organizations: A person-situation interactionist model. Academy of Management Review, 11(3), 601-617.

Trường Đại học Bách Khoa-ĐH Đà Nẵng. (2017). Quyết định số 29/QĐ-ĐHBK Ban hành Quy định về liêm chính học thuật của Trương Đại học Bách Khoa - Đại học Đà Nã̃ng [Decision No. 29 / QD-DHBK Promulgating the Regulation on academic integrity of University of Technology - Danang University]. Retrieved February 20, 2020, from http://daotao.dut.udn.vn/Content/PDF/QuyChe/QCQD_DUT_2017_030_HuongDan_Trich Dan.pdf 
Trường Đại học Hoa Sen. (2013). Quyết định số 1741/QĐ-BGH. Ngày 08/10/2013. Ban hành Quy định về Liêm chính học thuật [Decision No. 1741 / QD-BGH. October 8, 2013. The regulation on academic integrity]. Retrieved March 20, 2020, from https://thuvien.hoasen.edu.vn/sites/default/files/thuvien/2018/user1288/qd-1741-liemchinh-hoc-thuat.pdf

Vu, G. C. (2018). "Liêm chính học thuật”: Lý luận, thực tiễn và những yêu cầu đặt ra trên thế giới và ở Việt Nam ["Academic integrity": Theory, practice and requirements set out in the world and in Vietnam]. Tạp chí Nghiên cứu Lập pháp, 6(238), 3-17.

Western Sydney University. (2020). Why is academic integrity important? Retrieved April 4, 2020, from https://www.westernsydney.edu.au/studysmart/home/academic_integrity _and_plagiarism/why_is_it_important

Yang, S. C., Chiang, F. K., \& Huang, C. L. (2017). A comparative study of academic dishonesty among university students in Mainland China and Taiwan. Asia Pacific Education Review, $18(3), 385-399$. 


\section{PHỤ LỤC A}

Kết quả kiểm định quan hệ (2 biến ordinal)

\begin{tabular}{|c|c|c|c|c|c|c|c|c|}
\hline & $\begin{array}{l}\text { KIỂM ĐỊNH QUAN HỆ } \\
\text { Kendall's tau-b/c, Sommers' d, gamma }\end{array}$ & $\begin{array}{l}\text { Hành vi vi } \\
\text { phạm } \\
\text { *Xêp loại } \\
\text { [2 nhóm] }\end{array}$ & $\begin{array}{c}\text { Mức } \\
\text { nghiêm } \\
\text { trọng } \\
\text { *Xếp loại } \\
\text { [2 nhóm] }\end{array}$ & $\begin{array}{l}\text { Hành vi vi } \\
\text { phạm } \\
\text { *Năm học }\end{array}$ & $\begin{array}{l}\text { Mức nghiêm } \\
\text { trọng } \\
\text { *Năm học }\end{array}$ & $\begin{array}{l}\text { Hành vi vi } \\
\text { phạm } \\
\text { *Mức } \\
\text { nghiêm } \\
\text { trọng của } \\
\text { hành vi }\end{array}$ & $\begin{array}{l}\text { Hành vi vi } \\
\text { phạm } \\
\text { *Mức } \\
\text { nghiêm } \\
\text { khắc xử lý } \\
\text { gian lận HT }\end{array}$ & $\begin{array}{l}\text { Hành vi vi } \\
\text { phạm*Cảm } \\
\text { nhận của } \\
\text { SV về mức } \\
\text { nhận thức } \\
\text { của GV đối } \\
\text { với gian lận } \\
\text { HT }\end{array}$ \\
\hline 1 & Làm bài tập chung khi yêu cầu cá nhân & & & {$[2]<[1]<[3]<[4]$} & & & & \\
\hline 2 & Lấy bài giải và đề kiểm tra của lớp khác để chuẩn bị & & & {$[2]<[1]<[3]<[4]$} & & $\mathbf{C}(+)$ & & \\
\hline 3 & Làm giúp, chỉ bài cho bạn khi kiểm tra & & & {$[1]<[2]<[3]<[4]$} & & & & \\
\hline 4 & Sửa, làm giả dữ liệu khi làm bài tập, báo cáo & & & {$[1]<[2]<[3]<[4]$} & {$[1]>[2]>[3]>[4]$} & $\mathbf{C}(+)$ & & \\
\hline 5 & Xem bài bạn khi kiểm tra, được bạn ĐÔNNG Ý & {$[3]<[4]$} & & {$[1]<[2]<[3]<[4]$} & {$[1]>[2,3]>[4]$} & * & & \\
\hline 6 & Xem bài bạn khi kiểm tra, KHÔNG được đồng ý & & & & {$[1]>[2,3,4]$} & & & \\
\hline 7 & Sử dụng tin nhắn, Zalo để nhờ bạn làm giúp khi kiểm & {$[3]<[4]$} & & {$[1]<[2,3]<[4]$} & {$[1]>[2,3,4]$} & $\mathbf{C}(+)$ & & \\
\hline 8 & Nhờ người khác làm hộ bài tập về nhà & {$[3]<[4]$} & & & {$[1]>[2,4]>[3]$} & * & & $\mathrm{C}(+)$ \\
\hline 9 & Sao chép bài tập về nhà của bạn qua máy tính, Zalo & & & {$[1]<[2]<[3]<[4]$} & & * & & \\
\hline 10 & Sao chép bài tập về nhà của bạn bằng tay & & & {$[1,2]<[3]<[4]$} & {$[1]>[3,4]>[2]$} & & & \\
\hline 11 & Copy từ sách, báo, tạp chí (giấy) không dẫn nguồn & & {$[3]>[4]$} & {$[1]<[2]<[3]<[4]$} & & $\mathbf{C}(+)$ & & \\
\hline 12 & Copy từ Internet không dẫn nguồn & & & {$[1]<[2]<[3,[4]$} & & * & & \\
\hline 13 & Sử dụng bài làm cũ của người khác để nộp & {$[3]>[4]$} & & {$[1]<[2]<[3]<[4]$} & & $\mathbf{C}(+)$ & & \\
\hline 14 & Mua các bài làm để nộp & & {$[3]>[4]$} & {$[1,2,3]<[4]$} & & & & \\
\hline 15 & Sử dụng tài liệu viết tay không được phép khi thi & & {$[3]>[4]$} & {$[1,2<[3]<[4]$} & & $\mathbf{C}(+)$ & & \\
\hline 16 & Sử dụng tài liệu trong bộ nhớ thiết bị điện tử khi thi & & {$[3]>[4]$} & & & & $\mathrm{C}(-)$ & \\
\hline 17 & Sử dụng thiết bị điện tử khi thi & {$[3]<[4]$} & {$[3]>[4]$} & & & $\mathbf{C}(+)$ & & \\
\hline 18 & Sao chép một phần bài làm của người khác & & & {$[1]<[2,3,4]$} & & $\mathbf{C}(+)$ & & \\
\hline 19 & Đưa lý do giả tạo để nộp bài trễ hạn & & & & {$[1]>[2]>[3]>[4]$} & & C(-) & \\
\hline 20 & Không làm, sử dụng bài người khác để nộp & & {$[3]>[4]$} & & & $\mathbf{C}(+)$ & $\mathbf{C}(-)$ & \\
\hline
\end{tabular}




\section{KIỂM ĐỊNH QUAN HỆ}

Kendall's tau-b/c, Sommers' d, gamma
Hành vi vi

phạm

*Mức hiệu

quả chính

sách gian lận nghiêm

Hành vi vi Hành vi vi

phạm

phạm

*Phản ứng

*Phản ứng

cua ban học của cha me

Mức trọng của

nghiêm

trọng của

hành

vi*Mức

nghiêm

hành vi*

Cảm nhận

của $\mathrm{SV}$ về

mức nhận

thức của

\section{Mức}

nghiêm

trọng của

hành

vi*Mức

hiệu quả

hính sá

khắc xử lý

GV đối với

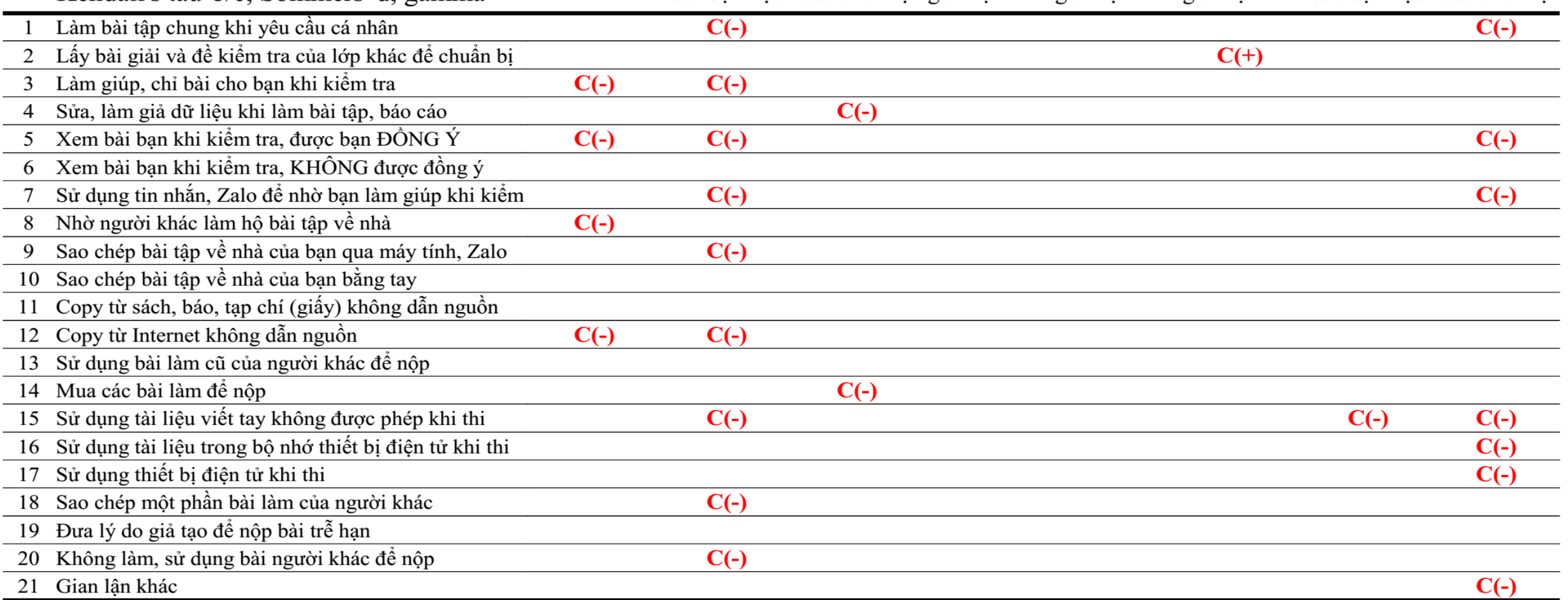

ian lận HT

Mức Mức

nghiêm nghiêm

trọng của trọng của

hành vi hành vi

*Phản ứng *Phản ứng

của ban hoc

Ghi chú: Xếp loại: [3], [4] tương ứng với điểm trung bình tích lũy [A-B] và [C-D]

Năm học: [1], [2], [3], [4] tương ứng sinh viên năm 1 đến năm 4

$\mathrm{C}(+), \mathrm{C}(-)$ lần lượt là tương quan thuận và nghịch

Nguồn: Kết quả phân tích dữ liệu của nhóm nghiên cứu 